\title{
Negative Control
}

National Cancer Institute

\section{Source}

National Cancer Institute. Negative Control. NCI Thesaurus. Code C64357.

A control sample where a negative result is expected, to help correlate a positive result with the variable being tested. 